Check for updates

Cite this: RSC Adv., 2019, 9, 29015

\title{
Mxene/alginate composites for lead and copper ion removal from aqueous solutions
}

\author{
Yanjie Dong, (D)* Dashen Sang, Chengdong He, Xinfeng Sheng and Longwen Lei \\ Mxene has been widely used as a sorbent to remove heavy metal ions from sewage due to its unique two- \\ dimensional layered structure and abundant oxygen-containing groups. However, Mxene has a relatively \\ limited adsorption capacity for metal ions possibly due to the limited adsorption active sites. Herein, we \\ reported novel Mxene/alginate composites for lead and copper ion removal from wastewater. The \\ Mxene/alginate composites prepared in this study not only enhance the chelation ability of the lead and \\ copper ions, but also accelerate the ion transport efficiency. The combined advantages of high \\ adsorption capacity and short equilibrium time enable the Mxene/alginate composites to achieve the \\ maximum adsorption capacity for $\mathrm{Pb}^{2+}$ and $\mathrm{Cu}^{2+}$ at 382.7 and $87.6 \mathrm{mg} \mathrm{g}^{-1}$, respectively, and reach the \\ adsorption equilibrium in $15 \mathrm{~min}$. We believe that the composites developed in this study can open \\ a new avenue for designing high adsorption capacity and high efficiency adsorbents.
}

Received 10th July 2019

Accepted 31st August 2019

DOI: 10.1039/c9ra05251h

rsc.li/rsc-advances

In this study, we designed and fabricated Mxene/alginate

\section{Introduction}

With the rapid development of industrial economy, heavy metal pollution has become one of the most serious environmental problems in recent decades. ${ }^{1}$ The treatment of heavy metals is of special concern given their toxicity and persistence in the environment. There is no doubt that it poses a great threat to the ecological environment and human health. ${ }^{1,2}$ Thus, the ability to efficiently remove heavy metal ions from water has gradually become the focus of environmental researchers.

In recent years, with the development of wastewater technologies, such as adsorption, membrane filtration, chemical precipitation and ion exchange, great progress has been made in the treatment and purification of heavy metals in wastewater. ${ }^{3-5}$ Among these methods, adsorption is regarded as a promising method given its simple operation, high treatment efficiency, low-cost, and excellent recyclability. ${ }^{6}$

Mxene, a new graphene-like 2D material, has a wide range of applications in energy storage, catalysis and sewage treatment due to its unique layered structure and hydrophilic surface. Shahzad et al. synthesized $\mathrm{Ti}_{3} \mathrm{C}_{2} \mathrm{~T}_{x}$ Mxene nanosheets for an efficient copper removal from water. ${ }^{7}$ Ying et al. fabricated $2 \mathrm{D}$ $\mathrm{Ti}_{3} \mathrm{C}_{2} \mathrm{~T}_{x}$ with regular structure by HF etching, which showed superior performance for the adsorption of chromium. ${ }^{8}$ These Mxene materials have shown potential in the treatment of heavy metals. However, $\mathrm{Ti}_{3} \mathrm{C}_{2} \mathrm{~T}_{x}$ as a single adsorption material has a relatively limited adsorption capacity for heavy metal ions due to the limited active sites.

Anhui Provincial Laboratory of Optoelectronic and Magnetism Functional Materials, College of Chemistry and Chemical Engineering, Anqing Normal University, Anqing, 246011, People's Republic of China. E-mail: dongyjaqtc@126.com composites to overcome the problem of limited adsorption capacity in a single Mxene. A large number of amino and carboxyl groups in alginate have good chelating ability for heavy metal ions, which can significantly increase the adsorption capacity of the composites. In addition, the 2D lamellar structure of the composites can greatly improve the transport efficiency of heavy metal ions in the adsorption process and significantly shorten the time required to reach the adsorption equilibrium. Here, we demonstrated that Mxene/alginate composites are indeed a promising sorbent for heavy metal treatment.

\section{Experimental}

\subsection{Reagents}

Sodium alginate, nitric acid, calcium nitrate, hydrofluoric acid, titanium aluminum carbide $\left(\mathrm{Ti}_{3} \mathrm{AlC}_{2}\right)$, lead nitrate $\left(\mathrm{Pb}\left(\mathrm{NO}_{3}\right)_{2}\right)$, and copper nitrate trihydrate $\left(\mathrm{Cu}\left(\mathrm{NO}_{3}\right)_{2} \cdot 3 \mathrm{H}_{2} \mathrm{O}\right)$ were purchased from the Shanghai Aladdin Biochemical Technology Co., Ltd. All reagents were of analytical grade and were used without further purification, and deionized water was used as a solvent throughout this study.

\subsection{Apparatus}

Scanning electron microscopy (SEM, FEI Sirion 200, Eindhoven, the Netherlands) was used to characterize the surface morphology of samples. Fourier transform infrared spectroscopy (FT-IR, Thermo Nicolet 6700, Waltham, USA) and X-ray photoelectron spectroscopy (XPS, Shimadzu Axis-Ultra DLD, Tokyo, Japan) were performed in this study to acquire the material composition analysis. The metal ion concentrations before and after adsorption were confirmed by inductively coupled plasma-optical emission spectrometry (ICPOES, PerkinElmer Optima 8000, Waltham, USA). 


\subsection{Fabrication of $\mathrm{Ti}_{3} \mathrm{C}_{2} \mathrm{~T}_{x}$}

For the fabrication of $\mathrm{Ti}_{3} \mathrm{C}_{2} \mathrm{~T}_{x}, 2 \mathrm{~g} \mathrm{Ti}{ }_{3} \mathrm{AlC}_{2}$ was first added into $30 \mathrm{~mL} \mathrm{HF} \mathrm{(40 \%} \mathrm{aqueous} \mathrm{solution)} \mathrm{and} \mathrm{stirred} \mathrm{for} 12 \mathrm{~h}$. Then, the mixture was washed with deionized water several times until a $\mathrm{pH}$ value of 5 was achieved. Finally, $\mathrm{Ti}_{3} \mathrm{C}_{2} \mathrm{~T}_{x}$ was obtained by drying in a vacuum oven at $80{ }^{\circ} \mathrm{C}$ for $24 \mathrm{~h}$.

\subsection{Preparation of Mxene/alginate composites}

$0.16 \mathrm{~g} \mathrm{Ti}_{3} \mathrm{C}_{2} \mathrm{~T}_{x}$ and varying amounts of sodium alginate $(68,106$, $160,240,370$, and $640 \mathrm{mg}$ ) were first added into $20 \mathrm{~mL}$ deionized water, and the mixture was stirred with a magnetic stirrer for $6 \mathrm{~h}$. Then, the mixture was placed into an ultra-low temperature refrigerator for $12 \mathrm{~h}$. Finally, the Mxene/alginate composites were obtained by freeze-drying under vacuum for $24 \mathrm{~h}$. The cross-linked Mxene/alginate composites were also prepared in this study under the same condition using calcium nitrate $(0.2 \mathrm{M})$ as a cross-linker.

\subsection{Adsorption experiment}

To complete the adsorption test, Mxene/alginate composites were first soaked in $50 \mathrm{~mL}$ of $1.5 \mathrm{mM} \mathrm{Pb}^{2+}$ and $\mathrm{Cu}^{2+}$ solutions, respectively. The mixture was filtered after stirring for $15 \mathrm{~min}$. The unextracted $\mathrm{Pb}^{2+}$ and $\mathrm{Cu}^{2+}$ in the solution were confirmed by ICP-OES. Each adsorption and desorption for $\mathrm{Pb}^{2+}$ and $\mathrm{Cu}^{2+}$ was performed three times in parallel, and the corresponding ion concentration depended on the average of the three parallel experiments. The corresponding adsorption capacity $(Q, \mathrm{mg}$ $\left.\mathrm{g}^{-1}\right)$ and the percentage of adsorbed metal ions $(\eta, \%)$ were calculated using the following formulae:

$$
\begin{gathered}
\eta=\frac{\left(C_{\mathrm{i}}-C_{\mathrm{f}}\right)}{C_{\mathrm{i}}} \times 100 \% \\
Q=\frac{\left(C_{\mathrm{i}}-C_{\mathrm{f}}\right) V M}{m}
\end{gathered}
$$

where $C_{\mathrm{i}}$ and $C_{\mathrm{f}}$ represent the concentration of metal ions in solution before and after adsorption, respectively (mM); $V$ is the volume of the solution (L); $M$ is the molar mass of the metal ions $\left(\mathrm{g} \mathrm{mol}^{-1}\right)$; and $m$ is the mass of the Mxene/alginate composite ( $\mathrm{g}$ ).

\section{Results and discussion}

\subsection{Material characterization}

The preparation process of the Mxene/alginate composites is shown in Fig. 1A. The original $\mathrm{Ti}_{3} \mathrm{AlC}_{2}$ (MAX) shows an irregular morphology (Fig. 1B). After etching with hydrofluoric acid, $\mathrm{Ti}_{3} \mathrm{C}_{2} \mathrm{~T}_{x}$ (Mxene) presents a typical two-dimensional organ-like morphology (Fig. 1C). When alginate is added to the $\mathrm{Ti}_{3} \mathrm{C}_{2} \mathrm{~T}_{x}$, alginate tends to occupy the interlayer, and then cover a part of the surface of $\mathrm{Ti}_{3} \mathrm{C}_{2} \mathrm{~T}_{x}$. Compared with pure $\mathrm{Ti}_{3} \mathrm{C}_{2} \mathrm{~T}_{x}$, the Mxene/ alginate composites have a rougher surface (Fig. 1D), which provides a superior environment for $\mathrm{Pb}^{2+}$ and $\mathrm{Cu}^{2+}$ adsorption.

In addition, FT-IR analysis is conducted to explore the functional groups of sodium alginate and the Mxene/alginate composites. As shown in Fig. 2, the broad adsorption peak at $3210 \mathrm{~cm}^{-1}$ belongs to the $\mathrm{O}-\mathrm{H}$ stretching vibration. The adsorption peak at $2908 \mathrm{~cm}^{-1}$ and $1026 \mathrm{~cm}^{-1}$ are attributed to the aliphatic $\mathrm{C}-\mathrm{H}$ stretching vibration and $\mathrm{C}-\mathrm{O}$ stretching vibration in sodium alginate. The peaks at 1590 and $1399 \mathrm{~cm}^{-1}$ can be assigned to the vibrational modes of $\mathrm{C}=\mathrm{O}$ and $\mathrm{C}-\mathrm{O}$ in the carboxyl group. ${ }^{\mathbf{9} 10}$ Compared with the infrared spectrum of sodium alginate, there is a new adsorption peak corresponding to the Ti-O stretching vibration at $596 \mathrm{~cm}^{-1}$ in the spectra of the Mxene/alginate composites, which confirms that sodium alginate was successfully incorporated into the Mxene. ${ }^{11}$ Moreover, the peak shift from $3210 \mathrm{~cm}^{-1}$ in the sodium alginate to $3196 \mathrm{~cm}^{-1}$ in the Mxene/alginate composites suggest the formation of hydrogen bonds between sodium alginate and Mxene. ${ }^{12}$

\subsection{Effect of alginate ratio in Mxene/alginate composites}

In order to evaluate the influence of the ratio of sodium alginate on the ability of the Mxene/alginate composites to absorb $\mathrm{Pb}^{2+}$ and $\mathrm{Cu}^{2+}$, a series of Mxene/alginate composites with different ratios of
A
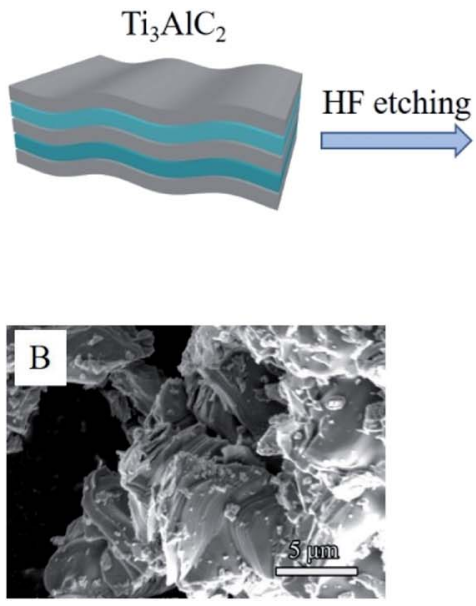
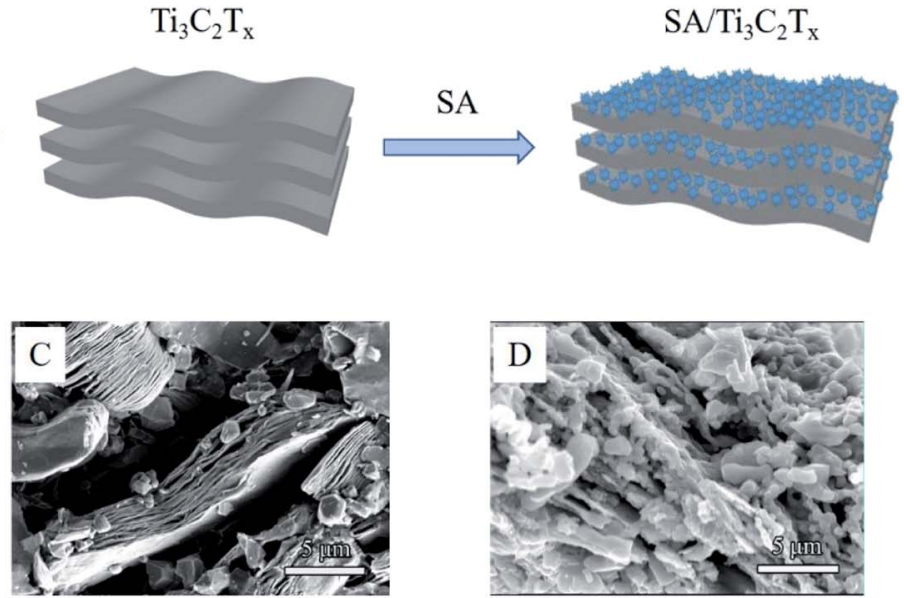

Fig. 1 (A) Schematic of the preparation of the Mxene/alginate composites; (B) surface morphology of $\mathrm{Ti}_{3} \mathrm{AlC}_{2}$; (C) surface morphology of $\mathrm{Ti}_{3} \mathrm{C}_{2} \mathrm{~T}_{x}$; (D) surface morphology of the Mxene/alginate composites. 


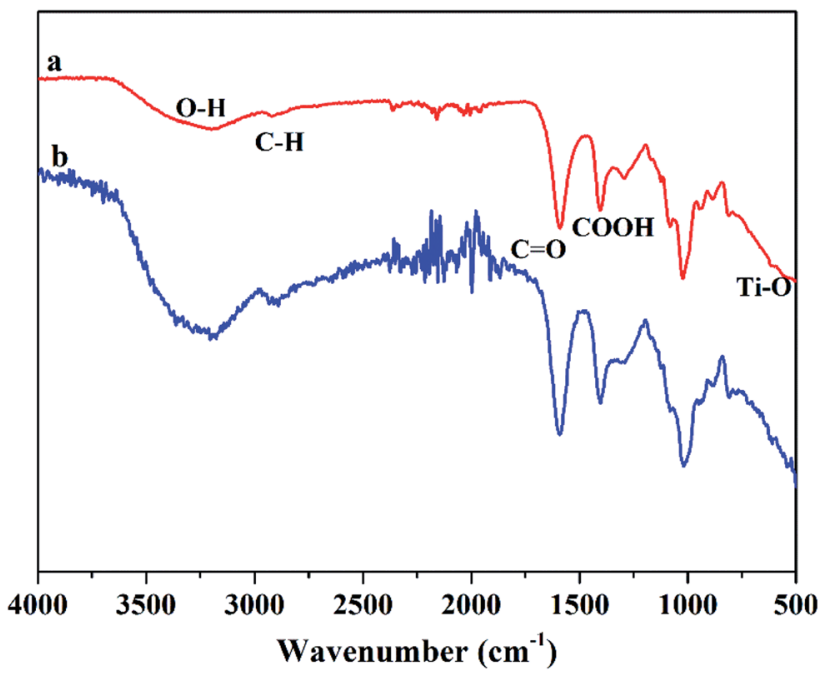

Fig. 2 FT-IR spectra of (a) Mxene/alginate composites and (b) sodium alginate.

sodium alginate were prepared in this study. As shown in Fig. 3, the adsorption efficiency of the Mxene/alginate composite for $\mathrm{Pb}^{2+}$ and $\mathrm{Cu}^{2+}$ increased with an increase in the ratio of sodium alginate and then remained relatively stable. This result can be explained by the large number of amino and carboxyl groups in sodium alginate, which can effectively chelate $\mathrm{Pb}^{2+}$ and $\mathrm{Cu}^{2+}$, and significantly improves the adsorption efficiency of the Mxene/alginate composites. However, when the ratio of sodium alginate continues to increase, sodium alginate not only fills the $\mathrm{Ti}_{3} \mathrm{C}_{2} \mathrm{~T}_{x}$ layer, but also covers the $\mathrm{Ti}_{3} \mathrm{C}_{2} \mathrm{~T}_{x}$ surface, thus possibly making $\mathrm{Ti}_{3} \mathrm{C}_{2} \mathrm{~T}_{x}$ lose part of its adsorption capacity. Therefore, the ratio of sodium alginate in $30-70 \%$ range, as the ratio of sodium alginate increase, the adsorption efficiency of the Mxene/alginate composites to $\mathrm{Pb}^{2+}$ and $\mathrm{Cu}^{2+}$ increase, the ratio of sodium alginate over $70 \%$, the adsorption efficiency of the Mxene/alginate composites to $\mathrm{Pb}^{2+}$ and $\mathrm{Cu}^{2+}$ decrease.

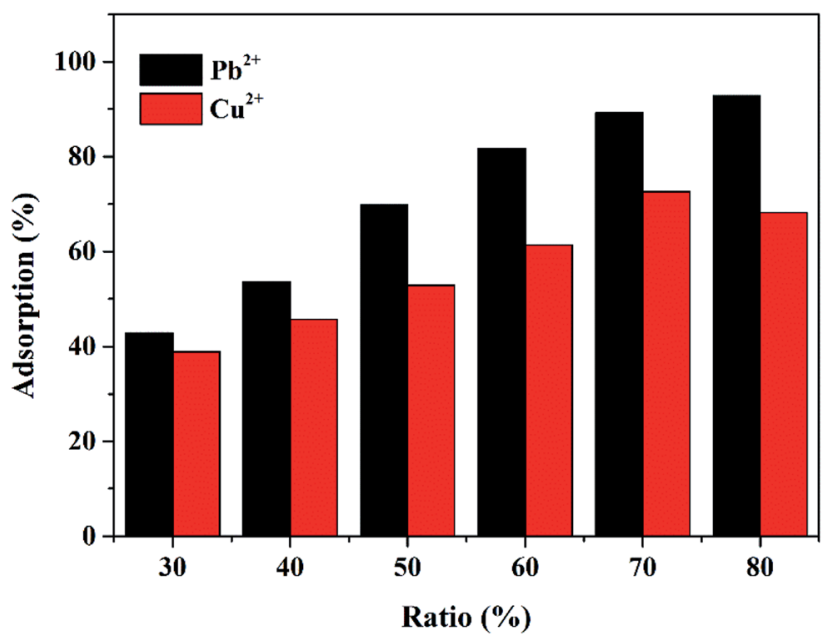

Fig. 3 Effect of alginate ratio in Mxene/alginate composite on $\mathrm{Pb}^{2+}$ and $\mathrm{Cu}^{2+}$ adsorption.

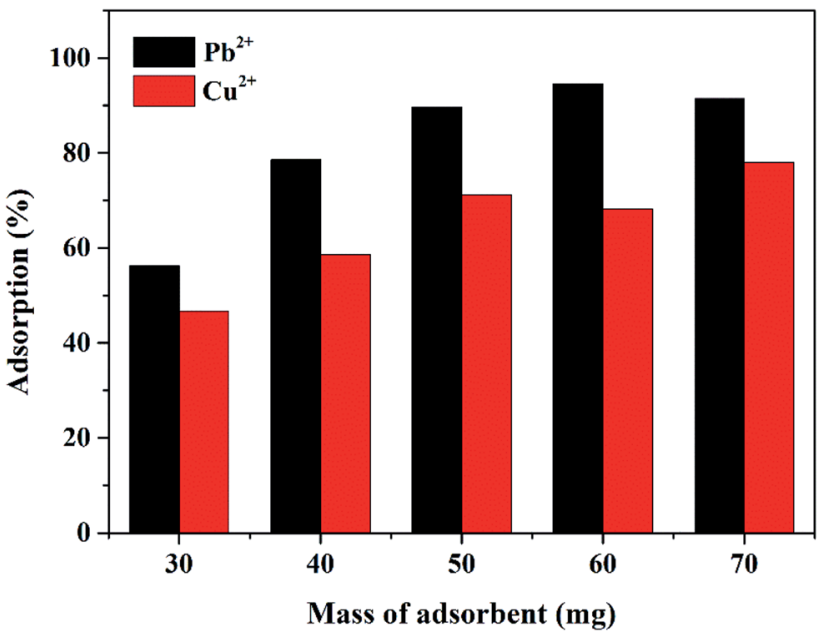

Fig. 4 Effect of composite sorbent dosage on $\mathrm{Pb}^{2+}$ and $\mathrm{Cu}^{2+}$ adsorption.

\subsection{Effect of Mxene/alginate composite sorbent dosage}

To obtain the superior adsorption performance, the Mxene/ alginate composite sorbent dosage was optimized in this study before exploring the adsorption capacity for $\mathrm{Pb}^{2+}$ and $\mathrm{Cu}^{2+}$. The corresponding results are presented in Fig. 4. When the composite adsorbent dosage was small $(<50 \mathrm{mg})$, the adsorption efficiency increased significantly with the increase in the adsorbent dosage. However, when the adsorbent dosage was equal to or more than $50 \mathrm{mg}$, there was a modest increment in the adsorption efficiency. This could be possibly due to the adequate adsorption active sites provided by the Mxene/alginate composite. Thus, $50 \mathrm{mg}$ of the Mxene/alginate composite adsorbent was used throughout the experiment.

\subsection{Effect of $\mathbf{p H}$}

The $\mathrm{pH}$ value of the solution is an important factor that influences the adsorption of heavy metals. Considering that the

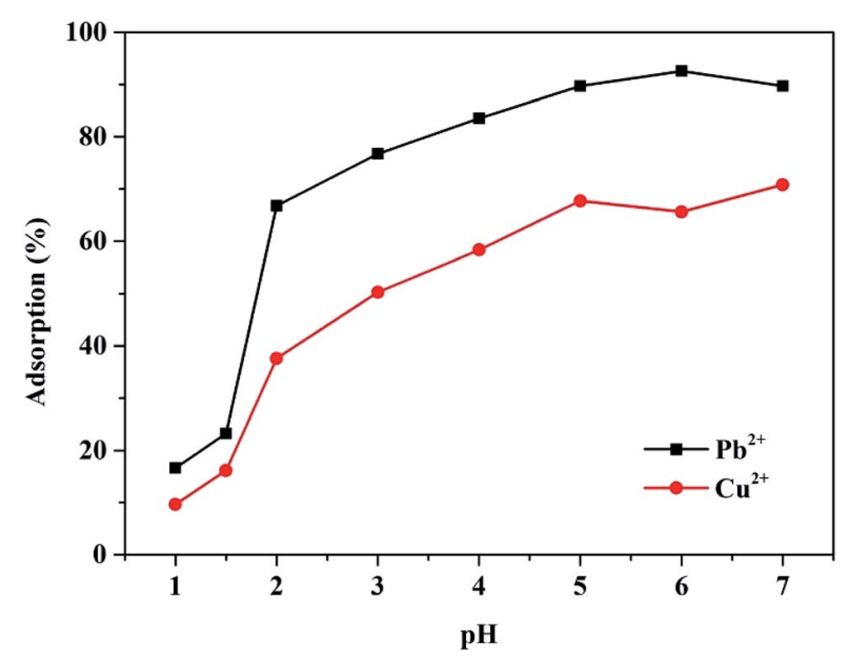

Fig. 5 Effect of $\mathrm{pH}$ on the adsorption of $\mathrm{Pb}^{2+}$ and $\mathrm{Cu}^{2+}$. 

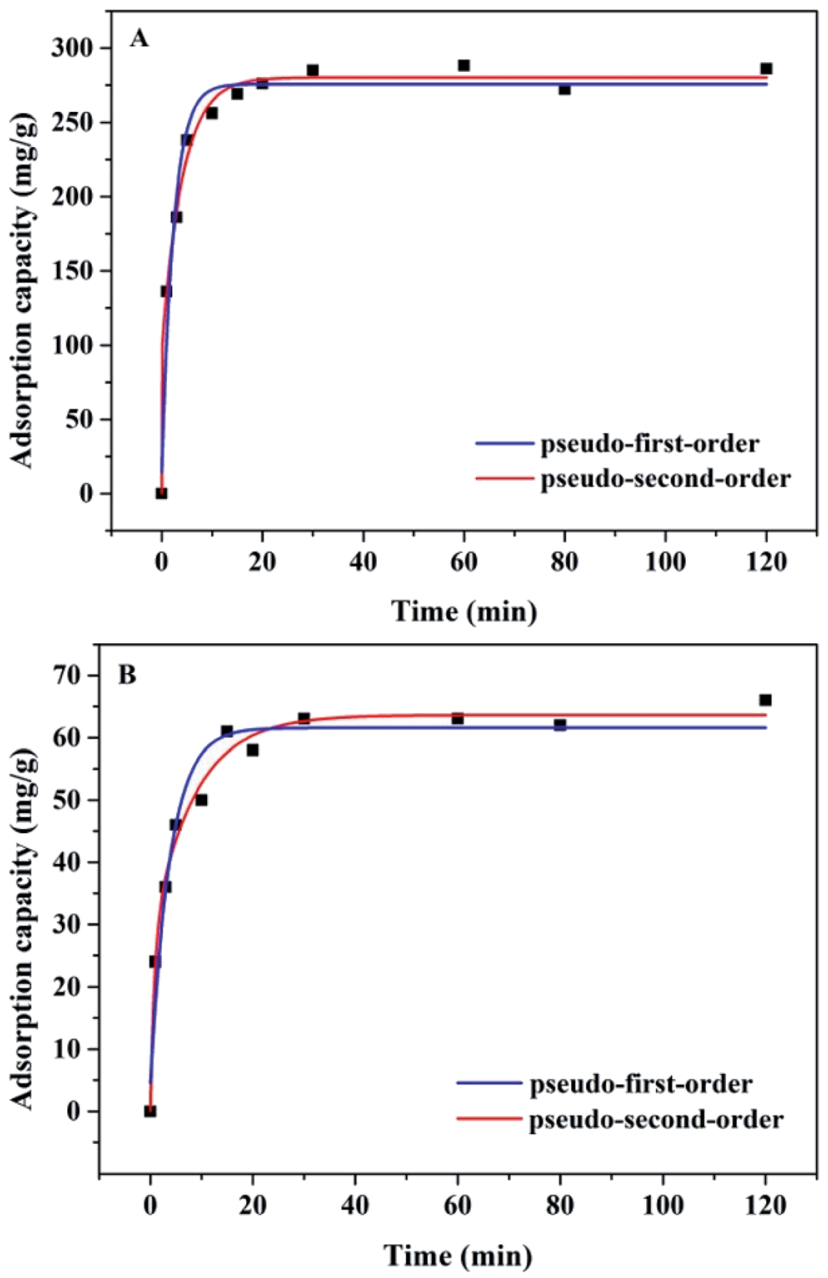

Fig. 6 Adsorption kinetics studies of (A) $\mathrm{Pb}^{2+}$ and (B) $\mathrm{Cu}^{2+}$ adsorption.

industrial heavy metal ion wastewater is usually acidic, the $\mathrm{pH}$ range was set to $\mathrm{pH}$ values of 1 to 7 in this study. As shown in Fig. 5, the adsorption efficiency of the Mxene/alginate composite to $\mathrm{Pb}^{2+}$ and $\mathrm{Cu}^{2+}$ was extremely limited when the aqueous solution was more acidic $(\mathrm{pH}<1)$. As the acidity of the solution decreased, the adsorption efficiency of the Mxene/ alginate composite to $\mathrm{Pb}^{2+}$ and $\mathrm{Cu}^{2+}$ was significantly improved. When the $\mathrm{pH}$ value reached a certain level $(\mathrm{pH} \geq 5)$,

Table 1 Kinetic parameters for $\mathrm{Pb}^{2+}$ and $\mathrm{Cu}^{2+}$ adsorption on the Mxene/alginate composites

\begin{tabular}{lllrr}
\hline Kinetic model & Formula & Parameters $\mathrm{Pb}^{2+}$ & \multicolumn{1}{c}{$\mathrm{Cu}^{2+}$} \\
\hline Pseudo-first-order & $q_{\mathrm{t}}=q_{\mathrm{e}}\left(1-\exp \left(-k_{1} t\right)\right)$ & $q_{\mathrm{e}}\left(\mathrm{mg} \mathrm{g}^{-1}\right)$ & 275.6403 & 61.5735 \\
& & $k_{1}(\mathrm{~L}$ & 0.2599 & 0.1206 \\
& & $\left.\min ^{-1}\right)$ & & \\
& & $R^{2}$ & 0.9661 & 0.9559 \\
Pseudo-second- & $q_{\mathrm{t}}=q_{\mathrm{e}}(1-1 /(1+$ & $q_{\mathrm{e}}\left(\mathrm{mg} \mathrm{g}^{-1}\right)$ & 280.1126 & 63.6194 \\
order & $\left.\left.q_{\mathrm{e}} k_{2} t\right)\right)$ & $k_{2}(\mathrm{~L}$ & 0.0069 & 0.0064 \\
& & $\left.\min ^{-1}\right)$ & & \\
& & $R^{2}$ & 0.9897 & 0.9839
\end{tabular}

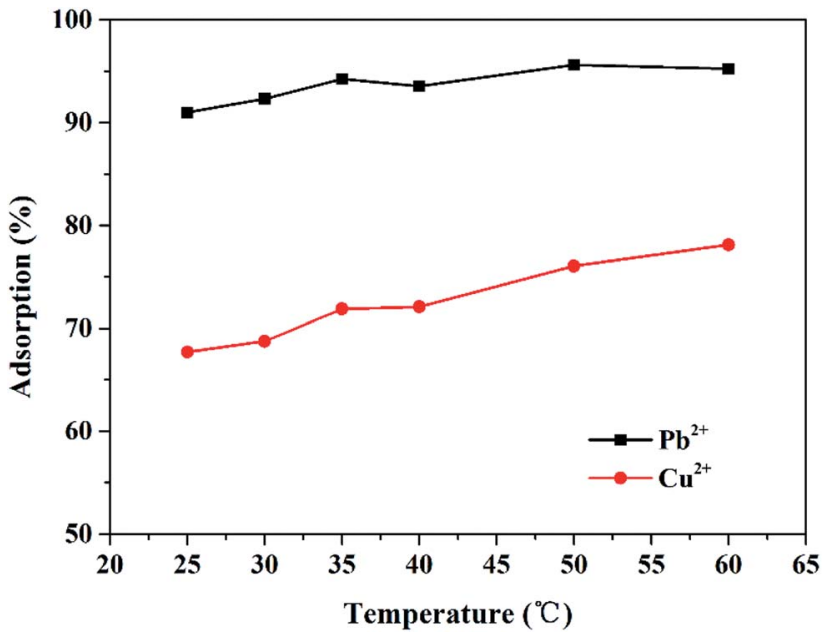

Fig. 7 Effect of temperature on $\mathrm{Pb}^{2+}$ and $\mathrm{Cu}^{2+}$ adsorption.

the adsorption curve of the Mxene/alginate composite on $\mathrm{Pb}^{2+}$ and $\mathrm{Cu}^{2+}$ appeared to plateau, which indicated that the adsorption of the Mxene/alginate composite on $\mathrm{Pb}^{2+}$ and $\mathrm{Cu}^{2+}$ was stabilized. This experimental phenomenon can be explained by competitive adsorption. When the $\mathrm{pH}$ value is small, a lot of $\mathrm{H}^{+}$and $\mathrm{H}_{3} \mathrm{O}^{+}$ions in the solution occupied the active sites on the surface of the adsorbent. In addition to the increased $\mathrm{pH}$ value of the solution, the ability of the $\mathrm{H}^{+}$and $\mathrm{H}_{3} \mathrm{O}^{+}$ions to occupy the adsorption sites decreases, and the heavy metal ions with positive charges begin to occupy the adsorption sites instead. Thus, the adsorption capacity of the adsorbent to $\mathrm{Pb}^{2+}$ and $\mathrm{Cu}^{2+}$ increases. ${ }^{10}$

\subsection{Effect of time and temperature}

The effect of time on the adsorption of $\mathrm{Pb}^{2+}$ and $\mathrm{Cu}^{2+}$ are shown in Fig. 6. It is obvious that the adsorption rate of $\mathrm{Pb}^{2+}$ and $\mathrm{Cu}^{2+}$ onto the Mxene/alginate composite was fast during the initial 15 min, which can adsorb $86.7 \% \mathrm{~Pb}^{2+}$ and $63.5 \% \mathrm{Cu}^{2+}$,

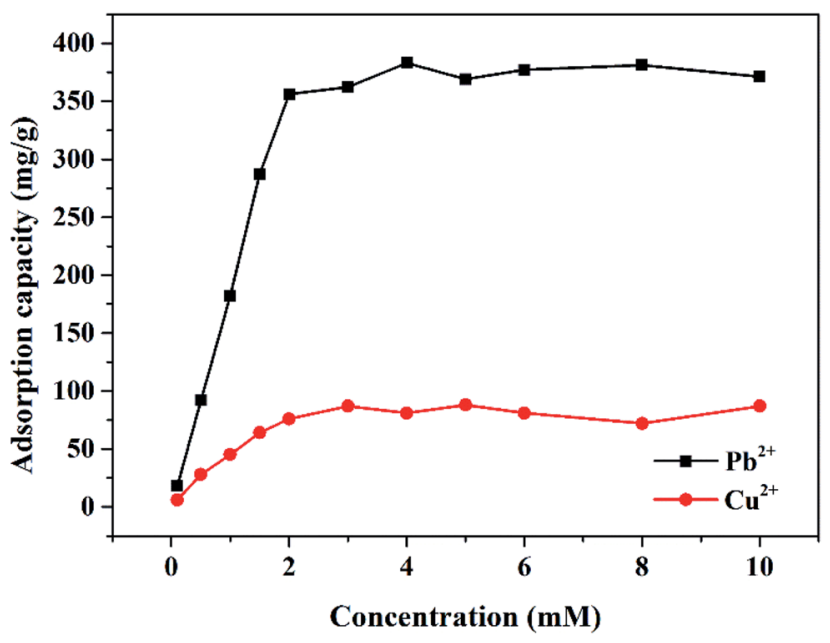

Fig. 8 Effect of ion concentration on $\mathrm{Pb}^{2+}$ and $\mathrm{Cu}^{2+}$ adsorption. 
Table 2 Maximum adsorption capacity of reported adsorbents for $\mathrm{Pb}^{2+}$ and $\mathrm{Cu}^{2+}$ removal from water

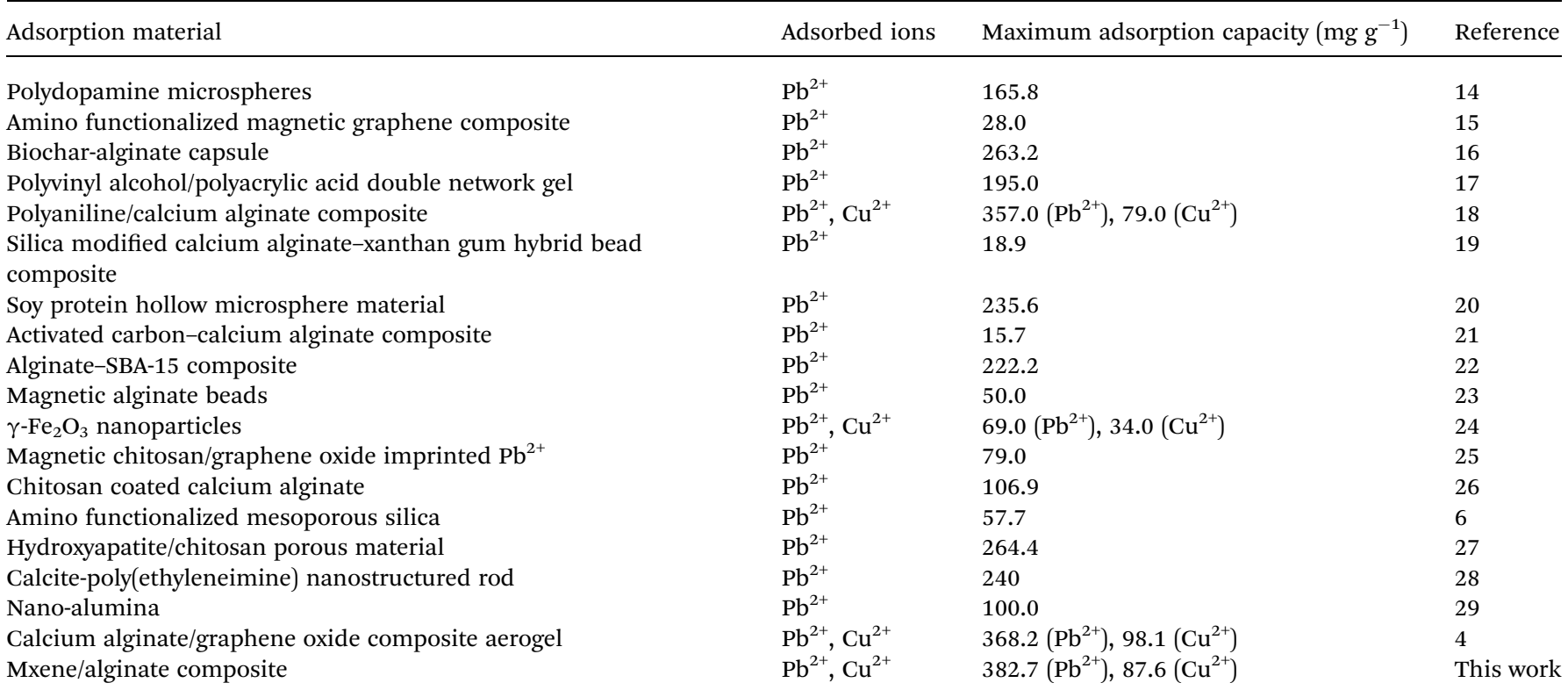
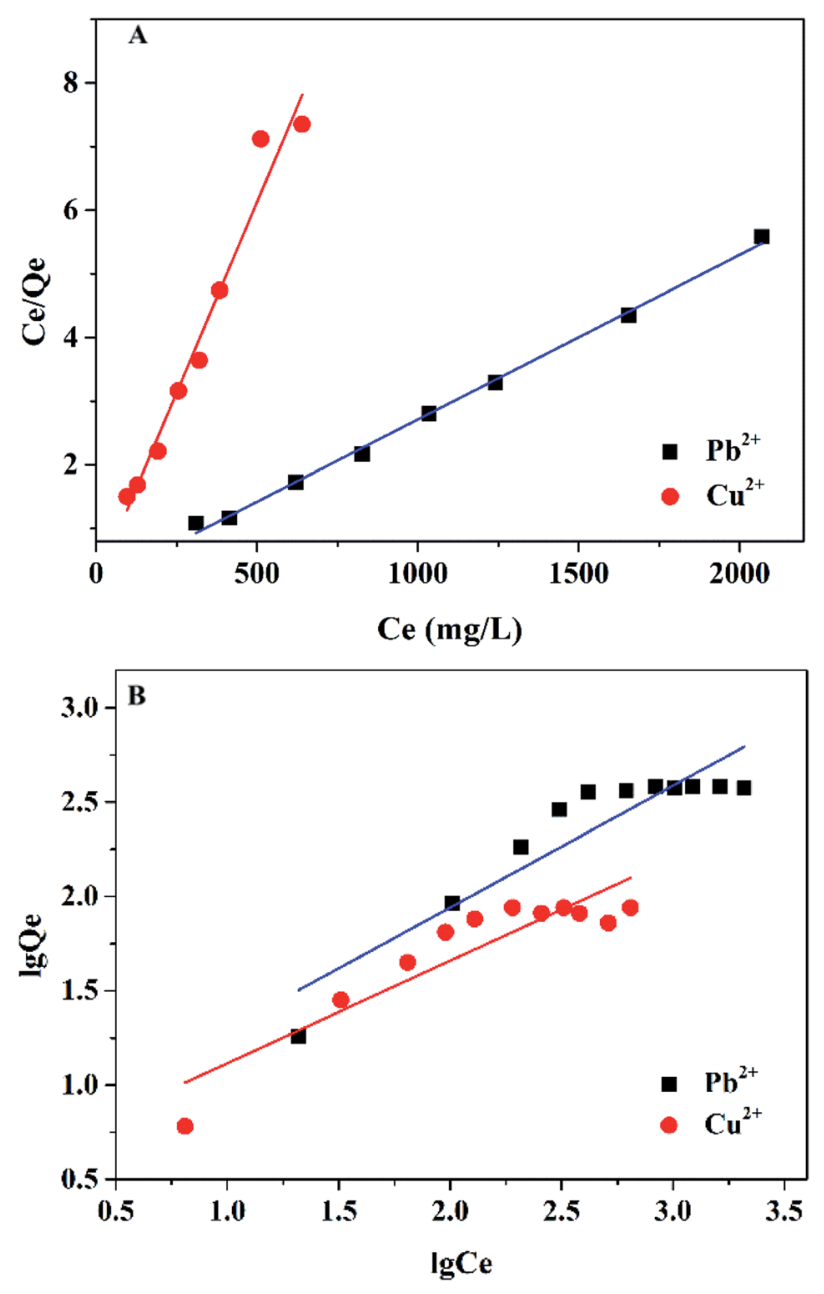

Fig. 9 (A) Langmuir and (B) Freundlich adsorption isotherm studies on $\mathrm{Pb}^{2+}$ and $\mathrm{Cu}^{2+}$. respectively. This is attributed to the abundant adsorption groups provided by sodium alginate and $\mathrm{Ti}_{3} \mathrm{C}_{2} \mathrm{~T}_{x}$. Furthermore, the short equilibrium time ( $15 \mathrm{~min}$ in this study) was obtained due to the $2 \mathrm{D}$ layered structure provided by $\mathrm{Ti}_{3} \mathrm{C}_{2} \mathrm{~T}_{x}$. This was conducive to the intercalation and diffusion of the ions, thus accelerating the transport efficiency of $\mathrm{Pb}^{2+}$ and $\mathrm{Cu}^{2+}$. As the reaction time progressed, the adsorption sites in the Mxene/ alginate composites were gradually occupied and the adsorption curve appeared as a plateau, indicating that the adsorption process reached equilibrium. In addition, in order to further study the kinetic behavior of adsorption, pseudo-first-order and pseudo-second-order models were adopted to match the relevant experiment data. The corresponding results shown in Fig. 6 and Table 1 illustrate that there is a better match for the pseudo-second-order kinetic model based on the values of $R^{2}$, which suggests that chemisorption plays an important role in the adsorption process. ${ }^{4,13}$

In addition, the effect of temperature was also investigated in this study. As displayed in Fig. 7, the adsorption efficiency of $\mathrm{Pb}^{2+}$ and $\mathrm{Cu}^{2+}$ generally increased with the increase in temperature, which demonstrate that the adsorption of $\mathrm{Pb}^{2+}$ and $\mathrm{Cu}^{2+}$ by the Mxene/alginate composite is an endothermic process. However, it is not clear that the improvement in the

Table 3 Isotherm parameters for $\mathrm{Pb}^{2+}$ and $\mathrm{Cu}^{2+}$ adsorption

\begin{tabular}{lllrc} 
Isotherm model & Formula & Parameters & $\mathrm{Pb}^{2+}$ & \multicolumn{1}{c}{$\mathrm{Cu}^{2+}$} \\
\hline \multirow{2}{*}{ Langmuir } & \multirow{2}{*}{$C / Q=C / Q_{\mathrm{e}}+1 /\left(Q_{\mathrm{e}} b\right)$} & $Q_{\mathrm{e}}\left(\mathrm{mg} \mathrm{g}^{-1}\right)$ & 380.56 & 83.52 \\
& & $b\left(\mathrm{~L} \mathrm{mg}^{-1}\right)$ & 0.067 & 0.011 \\
& & $R^{2}$ & 0.997 & 0.964 \\
Freundlich & \multirow{2}{*}{$\lg Q=\lg K+1 / n \lg C$} & $K\left(\mathrm{~L} \mathrm{mg}^{-1}\right)$ & 8.688 & 5.729 \\
& & $n$ & 1.528 & 2.728 \\
& & $R^{2}$ & 0.826 & 0.819
\end{tabular}



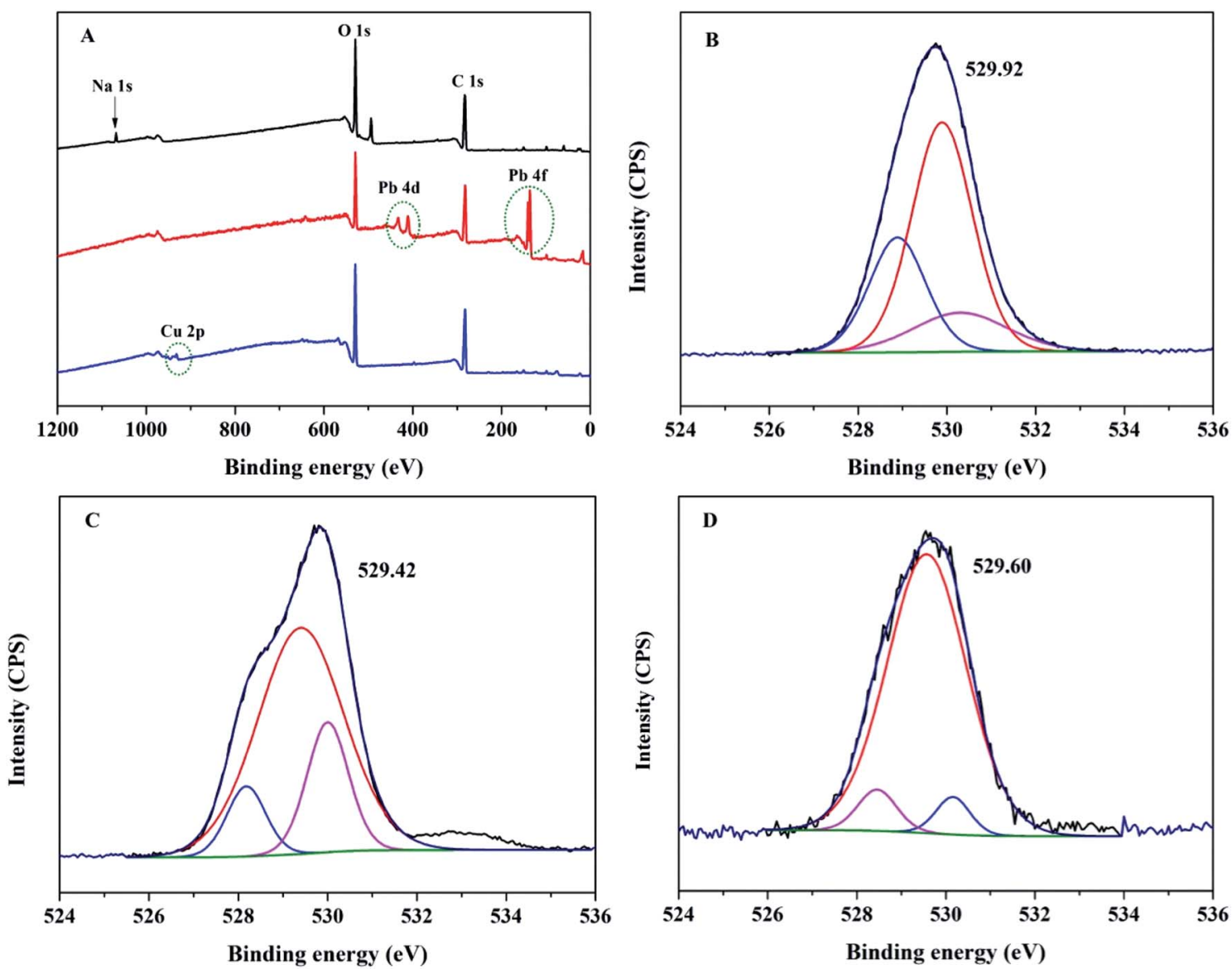

Fig. 10 (A) X-ray photoelectron spectra of Mxene/alginate composites before and after adsorption; (B, C and D) O 1s spectra of Mxene/alginate composites (B) before, (C) after $\mathrm{Pb}^{2+}$ and (D) after $\mathrm{Cu}^{2+}$ adsorption.

adsorption efficiency for $\mathrm{Pb}^{2+}$ and $\mathrm{Cu}^{2+}$ is caused by temperature, indicating that the temperature had little influence on ion migration. It may be that the two-dimensional layered structure provided by $\mathrm{Ti}_{3} \mathrm{C}_{2} \mathrm{~T}_{x}$ optimized the ion migration and intercalation, making the ion transport less dependent on temperature.

\subsection{Maximum adsorption capacity}

The maximum adsorption capacity of the Mxene/alginate composite for $\mathrm{Pb}^{2+}$ and $\mathrm{Cu}^{2+}$ was investigated and is displayed in Fig. 8. Initially, the adsorption capacity was significantly improved with the increase in ion concentration. Subsequently, there was no significant change in the adsorption capacity with an additional increase in ion concentration possibly due to the lack of active sites for the excess ions. The maximum adsorption capacities of the Mxene/alginate composite for $\mathrm{Pb}^{2+}$ and $\mathrm{Cu}^{2+}$ in this study were 382.7 and $87.6 \mathrm{mg} \mathrm{g}^{-1}$, respectively, which were higher values than that of most reported adsorbents for the removal of $\mathrm{Pb}^{2+}$ and $\mathrm{Cu}^{2+}$ from water. The reported maximum adsorption capacities of adsorbents for the removal of $\mathrm{Pb}^{2+}$ and $\mathrm{Cu}^{2+}$ from water are summarized in Table 2.

To acquire more accurate information about the interaction between the Mxene/alginate composite and heavy metal ions, Langmuir and Freundlich adsorption isotherm models were adopted in this study and are displayed in Fig. 9. The isotherm constants were calculated based on the experimental data and are presented in Table 3. The

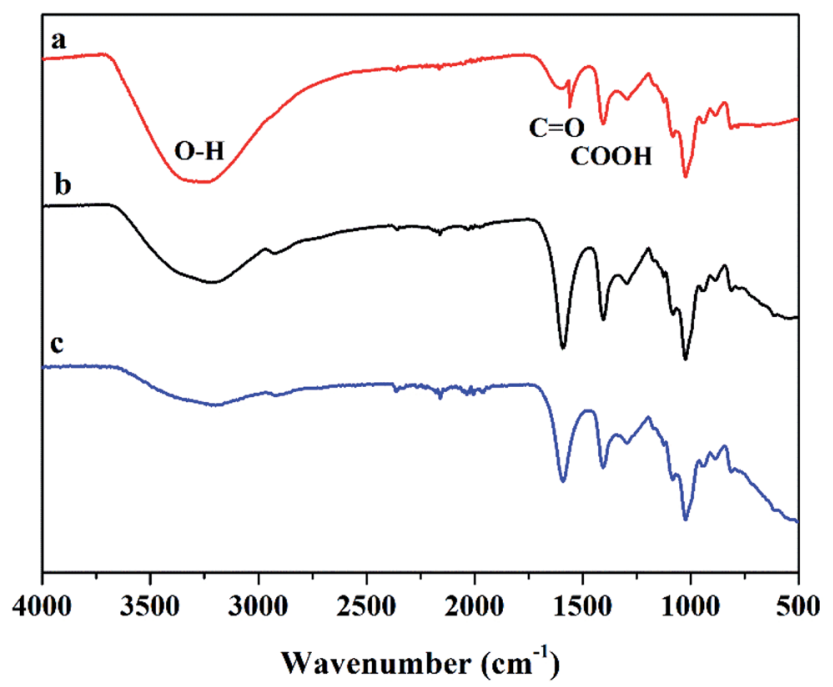

Fig. 11 FT-IR spectra of (a) Mxene/alginate composite, (b) Mxene/ alginate composite loaded $\mathrm{Pb}^{2+}$ and (c) Mxene/alginate composite loaded $\mathrm{Cu}^{2+}$. 
experimental results show that the Langmuir isotherm model exhibited a better correlation to describe the adsorption process compared with the Freundlich isotherm model, indicating that the adsorption process is more inclined to a monolayer adsorption.

\subsection{Adsorption mechanism}

To reveal the adsorption essence of the Mxene/alginate composites for $\mathrm{Pb}^{2+}$ and $\mathrm{Cu}^{2+}, \mathrm{X}$-ray photoelectron spectra of Mxene/alginate composites before and after adsorption were investigated. The disappearance of the $\mathrm{Na}$ 1s peak with the appearance of the $\mathrm{Pb} 4 \mathrm{~d}$ and $\mathrm{Pb} 4 \mathrm{f}$ (or $\mathrm{Cu} 2 \mathrm{p}$ ) peaks after adsorption of $\mathrm{Pb}^{2+}\left(\right.$ or $\left.\mathrm{Cu}^{2+}\right)$ suggests that ion exchange might be involved in the adsorption mechanism (Fig. 10A). To further explore the Mxene/alginate composite adsorption mechanism, the $\mathrm{O} 1 \mathrm{~s}$ peak was analyzed before and after $\mathrm{Pb}^{2+}$ and $\mathrm{Cu}^{2+}$-loading (Fig. 10B-D). The experimental results showed that the binding energy of the oxygencontaining function groups decreased slightly from 529.92 to 529.42 and $529.60 \mathrm{eV}$ after $\mathrm{Pb}^{2+}$ and $\mathrm{Cu}^{2+}$ adsorption, respectively. This result is consistent with the FT-IR results. The carboxylate peak of the composites shifted from 1410 to 1386 and $1398 \mathrm{~cm}^{-1}$ after the adsorption of $\mathrm{Pb}^{2+}$ and $\mathrm{Cu}^{2+}$ (Fig. 11), indicating that the chemical coordination of the oxygen atom of Mxene/alginate composites with $\mathrm{Pb}^{2+}$ and $\mathrm{Cu}^{2+}$ occurs during the adsorption process.

Based on the relevant XPS and FT-IR data analyses, a possible binding mechanism of the Mxene/alginate composites with $\mathrm{Pb}^{2+}$ and $\mathrm{Cu}^{2+}$ is a combination of the ion exchange and chemical coordination processes.

\subsection{Regeneration study}

In order to evaluate the practical application value of the Mxene/alginate composites, the regeneration performance of the Mxene/alginate composites was examined in this study (using $0.1 \mathrm{M}$ nitric acid solution as a desorption agent), and the recyclability of the composite adsorbents is depicted in Fig. 12. It is noteworthy to mention that the gelling of sodium alginate is mainly achieved by the exchange of sodium ions from the $\mathrm{G}$ residues with the divalent cations. The divalent cations bind to different chains of G blocks to form a structure like an "egg box," resulting in a three-dimensional network between the crosslinking of different chains. This enables the alginate to have better mechanical properties. ${ }^{30}$ When the Mxene/alginate composite was cross-linked, its regeneration performance was significantly improved compared with that of the uncross-linked Mxene/alginate composite. After four cycles, the adsorption rate was decreased significantly for the uncross-linked Mxene/alginate composite to $\mathrm{Pb}^{2+}$ and $\mathrm{Cu}^{2+}$. In this study, the adsorption loss rates of the cross-linked Mxene/alginate composite for $\mathrm{Pb}^{2+}$ and $\mathrm{Cu}^{2+}$ were $8.9 \%$ and $5.4 \%$ after ten cycles, respectively. These values are lower than those for the uncross-linked Mxene/alginate composite, which were $13.1 \%$ for $\mathrm{Pb}^{2+}$ and $12.7 \%$ for $\mathrm{Cu}^{2+}$. This may be because the composite structure has been
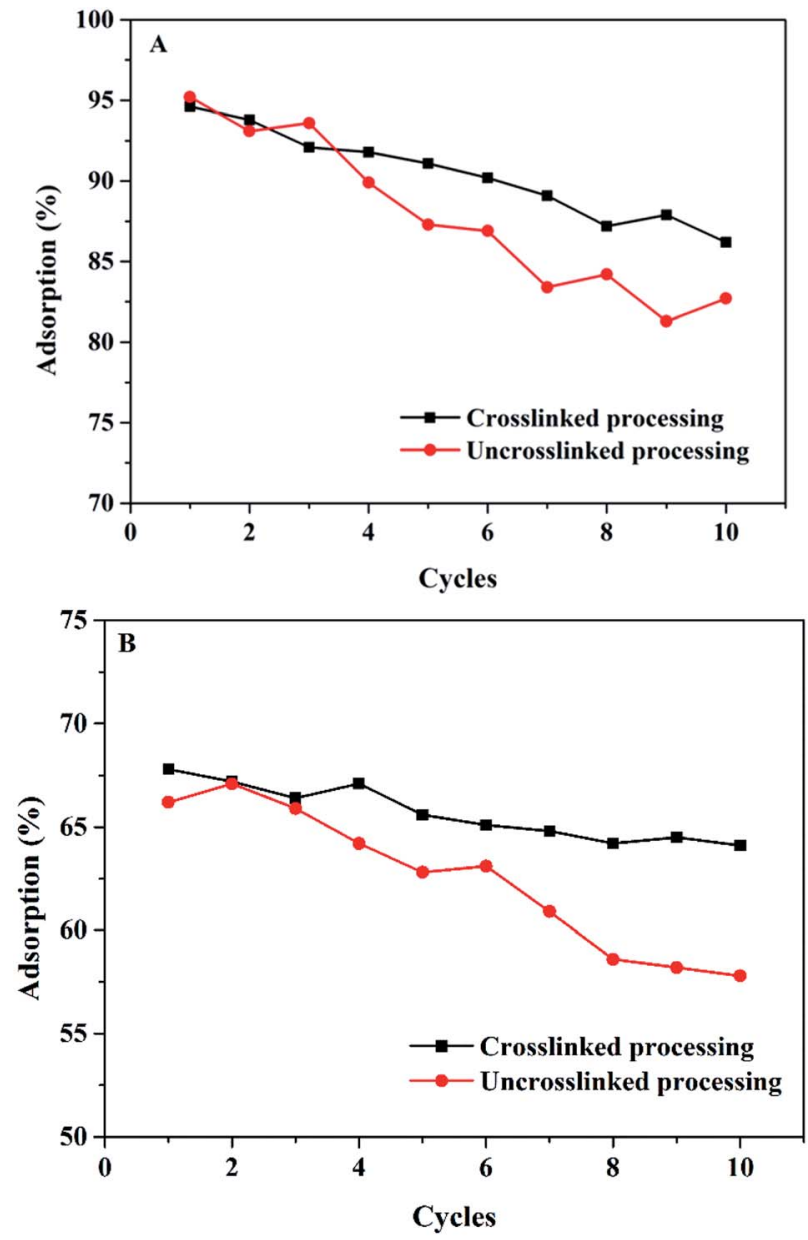

Fig. 12 Regeneration study of the Mxene/alginate composites for (A) $\mathrm{Pb}^{2+}$ and (B) $\mathrm{Cu}^{2+}$ adsorption.

damaged after repeated adsorption-desorption cycles. After cross-linking with calcium ions, the structural stability of the composites was improved. Thus, the adsorption loss rate had a significant decrease.

\section{Conclusions}

In this study, the Mxene/alginate composites with high adsorption capacity and short equilibrium times were investigated as a high-performance adsorbent for $\mathrm{Pb}^{2+}$ and $\mathrm{Cu}^{2+}$ removal. Its two-dimensional layered structure and abundant active adsorption sites enable the Mxene/alginate composite to achieve the maximum adsorption capacity for $\mathrm{Pb}^{2+}$ and $\mathrm{Cu}^{2+}$ at 382.7 and $87.6 \mathrm{mg} \mathrm{g}^{-1}$, respectively, and reach the adsorption equilibrium in $15 \mathrm{~min}$. Furthermore, the Mxene/alginate composites can be regenerated through a simple acid treatment and used without apparent loss in performance after cross-linking. The high capacity and efficiency, low temperature sensitivity, and simple regeneration treatment render the Mxene/alginate composites a promising adsorbent for heavy metal ions. 


\section{Conflicts of interest}

The authors declare no conflict of interest.

\section{Acknowledgements}

This study was funded by the National Natural Science Foundation of China (21203003, 21603003, 21601002/B010303), Anhui Provincial Natural Science Foundation (1708085MB49, 1708085QB43) and Key Project of Anhui Provincial Outstanding Young Scholars in Colleges and Universities (gxyqZD2017062).

\section{References}

1 B. Volesky, Hydrometallurgy, 2001, 59, 203-216.

2 E. Vunain, A. K. Mishra and B. B. Mamba, Int. J. Biol. Macromol., 2016, 86, 570-586.

3 S. Cataldo, G. Lazzara, M. Massaro, N. Muratore, A. Pettignano and S. Riela, Appl. Clay Sci., 2018, 156, 87-95.

4 L. H. Pan, Z. Q. Wang, Q. Yang and R. Y. Huang, Nanomaterials, 2018, 8, 957.

5 Y. D. Zou, X. X. Wang, A. Khan, P. Y. Wang, Y. H. Liu, A. Alsaedi, T. Hayat and X. K. Wang, Environ. Sci. Technol., 2016, 50, 7290-7304.

6 A. Heidari, H. Younesi and Z. Mehraban, Chem. Eng. J., 2009, 153, 70-79.

7 A. Shahzad, K. Rasool, W. Miran, M. Nawaz, J. Jang, K. A. Mahmoud and D. S. Lee, ACS Sustainable Chem. Eng., 2017, 5, 11481-11488.

8 Y. Ying, Y. Liu, X. Wang, Y. Mao, W. Cao, P. Hu and X. Peng, ACS Appl. Mater. Interfaces, 2015, 7, 1795-1805.

9 E. Ziaei, A. Mehdinia and A. Jabbari, Anal. Chim. Acta, 2014, 850, 49-56.

10 Y. G. Huang and Z. Q. Wang, Int. J. Biol. Macromol., 2018, 107, 741-747.

11 H. W. Pang, S. Y. Huang, Y. H. Wu, D. X. Yang, X. X. Wang, S. J. Yu, Z. S. Chen, A. Alsaedi, T. Hayat and X. K. Wang, Inorg. Chem. Front., 2018, 5, 2399-2407.

12 Y. Z. Wan, X. Q. Chen, G. Y. Xiong, R. S. Guo and H. L. Luo, Mater. Express, 2014, 4, 429-434.
13 Z. Q. Wang, P. X. Jin, M. Wang, G. H. Wu, J. Y. Sun, Y. J. Zhang, C. Dong and A. G. Wu, J. Chem. Technol. Biotechnol., 2018, 93, 2691-2700.

14 Q. R. Zhang, Q. G. Yang, P. Phanlavong, Y. X. Li, Z. K. Wang, T. F. Jiao and Q. M. Peng, ACS Sustainable Chem. Eng., 2017, 5, 4161-4170.

15 X. Y. Guo, B. Du, Q. Wei, J. Yang, L. H. Hu, L. G. Yan and W. Y. Xu, J. Hazard. Mater., 2014, 278, 211-220.

16 X. H. Do and B. K. Lee, J. Environ. Manage., 2013, 131, 375382.

17 L. Chu, C. B. Liu, G. Y. Zhou, R. Xu, Y. H. Tang, Z. B. Zeng and S. L. Luo, J. Hazard. Mater., 2015, 300, 153-160.

18 N. N. Jiang, Y. T. Xu, Y. Q. Dai, W. A. Luo and L. Z. Dai, J. Hazard. Mater., 2012, 215, 17-24.

19 S. Zhang, F. Xu, Y. F. Wang, W. Z. Zhang, X. L. Peng and F. Pepe, Chem. Eng. J., 2013, 234, 33-42.

20 D. G. Liu, Z. H. Li, W. Li, Z. R. Zhong, J. Q. Xu, J. J. Ren and Z. S. Ma, Ind. Eng. Chem. Res., 2013, 52, 11036-11044.

21 S. Cataldo, A. Gianguzza, D. Milea, N. Muratore and A. Pettignano, Int. J. Biol. Macromol., 2016, 92, 769-778.

22 R. Cheraghali, H. Tavakoli and H. Sepehrian, Sci. Iran., 2013, 20, 1028-1034.

23 A. Idris, N. S. M. Ismail, N. Hassan, E. Misran and A. F. Ngomsik, J. Ind. Eng. Chem., 2012, 18, 1582-1589.

24 S. Rajput, L. P. Singh, C. U. Pittman and D. Mohan, J. Colloid Interface Sci., 2017, 492, 176-190.

25 Y. H. Wang, L. L. Li, C. N. Luo, X. J. Wang and H. M. Duan, Int. J. Biol. Macromol., 2016, 86, 505-511.

26 N. E. Mousa, C. M. Simonescu, R. E. Patescu, C. Onose, C. Tardei, D. C. Culita, O. Oprea, D. Patroi and V. Lavric, React. Funct. Polym., 2016, 109, 137-150.

27 Y. Lei, J. J. Guan, W. Chen, Q. F. Ke, C. Q. Zhang and Y. P. Guo, RSC Adv., 2015, 5, 25462-25470.

28 A. M. L. Marzo, J. Pons and A. Merkoci, J. Mater. Chem. A, 2013, 1, 13532-13541.

29 A. Afkhami, M. Saber-Tehrani and H. Bagheri, J. Hazard. Mater., 2010, 181, 836-844.

30 C. L. Jiao, J. Q. Xiong, J. Tao, S. J. Xu, D. S. Zhang, H. Lin and Y. Y. Chen, Int. J. Biol. Macromol., 2016, 83, 133-141. 